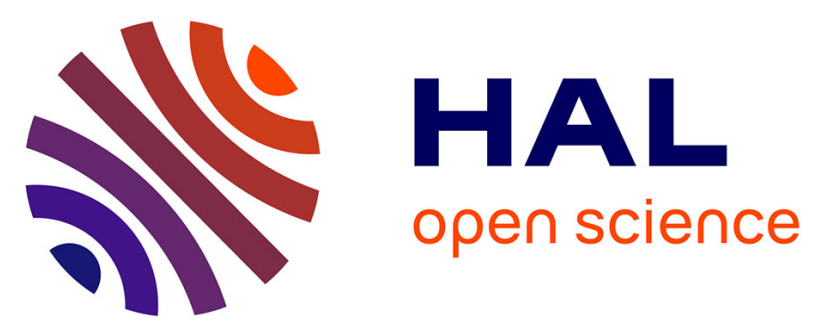

\title{
Expression of transient receptor potential vanilloid-1 (TRPV1) in urothelial cancers of human bladder: relation to clinico-pathological and molecular parameters.
}

Sara Caprodossi, Cristina Kalogris, Consuelo Amantini, Federica

Lambertucci, Massimo Nabissi, Maria Beatrice Morelli, Valerio Farfariello, Alessandra Filosa, Maria Cristina Emiliozzi, Gabriele Mammana, et al.

\section{To cite this version:}

Sara Caprodossi, Cristina Kalogris, Consuelo Amantini, Federica Lambertucci, Massimo Nabissi, et al.. Expression of transient receptor potential vanilloid-1 (TRPV1) in urothelial cancers of human bladder: relation to clinico-pathological and molecular parameters.. Histopathology, 2010, 57 (5), pp.744. 10.1111/j.1365-2559.2010.03683.x . hal-00593446

\author{
HAL Id: hal-00593446 \\ https://hal.science/hal-00593446
}

Submitted on 16 May 2011

HAL is a multi-disciplinary open access archive for the deposit and dissemination of scientific research documents, whether they are published or not. The documents may come from teaching and research institutions in France or abroad, or from public or private research centers.
L'archive ouverte pluridisciplinaire HAL, est destinée au dépôt et à la diffusion de documents scientifiques de niveau recherche, publiés ou non, émanant des établissements d'enseignement et de recherche français ou étrangers, des laboratoires publics ou privés. 


\section{Histopathology}

\section{Expression of transient receptor potential vanilloid-1 (TRPV1) in urothelial cancers of human bladder: relation to clinico-pathological and molecular parameters.}

\begin{tabular}{|c|c|}
\hline Journal: & Histopathology \\
\hline Manuscript ID: & HISTOP-07-09-0430.R2 \\
\hline Manuscript Type: & Original Article \\
\hline $\begin{array}{r}\text { Date Submitted by the } \\
\text { Author: }\end{array}$ & 18-Jan-2010 \\
\hline Complete List of Authors: & $\begin{array}{l}\text { Caprodossi, Sara; University of Camerino, Department of } \\
\text { Experimental Medicine and Public Health } \\
\text { Kalogris, Cristina; University of Camerino, Department of } \\
\text { Experimental Medicine and Public Health } \\
\text { Amantini, Consuelo; University of Camerino, Department of } \\
\text { Experimental Medicine and Public Health } \\
\text { Lambertucci, Federica; ASUR 9, Pathology and Cytodiagnostic Unit } \\
\text { Nabissi, Massimo; University of Camerino, Department of } \\
\text { Experimental Medicine and Public Health } \\
\text { Morelli, Maria Beatrice; University Sapienza, Department of } \\
\text { Experimental Medicine; University of Camerino, Department of } \\
\text { Experimental Medicine and Public Health } \\
\text { Farfariello, Valerio; University Sapienza, Department of } \\
\text { Experimental Medicine; University of Camerino, Department of } \\
\text { Experimental Medicine and Public Health } \\
\text { Filosa, Alessandra; ASUR 9, Pathology and Cytodiagnostic Unit } \\
\text { Emiliozzi, Maria Cristina; ASUR 9, Pathology and Cytodiagnostic } \\
\text { Unit } \\
\text { Mammana, Gabriele; ASUR 9, Urology Operative Unit } \\
\text { Santoni, Giorgio; University of Camerino, Department of } \\
\text { Experimental Medicine and Public Health }\end{array}$ \\
\hline Keywords: & $\begin{array}{l}\text { Bladder; Urothelium; Transitional cell carcinoma; Transient receptor } \\
\text { potential vanilloid type-1 (TRPV1); Kaplan-Meier; Survival }\end{array}$ \\
\hline
\end{tabular}

\section{ScholarONE" \\ Manuscript Central}


Expression of transient receptor potential vanilloid-1 (TRPV1) in urothelial cancers of human bladder: relation to clinico-pathological and molecular parameters.

Cristina Kalogris, Sara Caprodossi, Consuelo Amantini, Federica Lambertucci ${ }^{1}$, Massimo Nabissi, Maria Beatrice Morelli ${ }^{2}$, Valerio Farfariello ${ }^{2}$, Alessandra Filosa ${ }^{1}$, Maria Cristina Emiliozzi ${ }^{1}$, Gabriele Mammana ${ }^{3}$ and Giorgio Santoni.

Department of Experimental Medicine and Public Health, University of Camerino, Camerino (MC), Italy; ' Pathology and Cytodiagnostic Unit, ASUR 9, Macerata, Italy; ${ }^{2}$ Department of Experimental Medicine, University "Sapienza”, Rome, Italy; ${ }^{3}$ Urology Operative Unit, ASUR 9, Macerata, Italy.

Address for correspondence:

Prof. Giorgio Santoni

Dept. of Experimental Medicine and Public Health University of Camerino

Via Madonna delle Carceri 9, 62032, Camerino (MC), Italy

Phone: +390737 403312/403319; Fax: +390737 403325

E-mail:giorgio.santoni@unicam.it

${ }^{*}$ C.K. and S.C. contributed equally to this work.

Running Title: TRPV1 as prognostic marker for human UCs.

Keywords: Bladder; Urothelium; Transitional cell carcinoma; Transient receptor potential vanilloid type-1 (TRPV1), Kaplan-Meier, Survival.

Abbreviations: BSA, bovine serum albumin; CI, Confidence Interval; CPS, capsaicin; HR, Hazard Ratio; NB, normal bladder; PBS, phosphate-buffered saline; qRT-PCR, Real Time PCR; TCC, transitional cell carcinoma; TRP, transient receptor potential; TRPV1, transient receptor potential vanilloid-1; UC, urothelial cancer. 
Abstract

Aims: The aim of this study was to evaluate the expression of transient receptor potential vanilloid type-1 chennel protein (TRPV1) in normal and tumor urothelial tissues; to correlate TRPV1 expression with clinico-pathological parameters and with disease-specific survival.

Methods and Results: TRPV1 expression was analyzed in normal and tumor urothelial samples at both mRNA and protein levels by Real-Time PCR and immunohistochemistry, respectively. TRPV1 down-regulation was found in UC specimens, which correlates with tumor progression. Moreover, TRPV1 mRNA levels were associated to clinico-pathological parameters to asses the role of TRPV1 down-regulation as a negative prognostic factor for survival. Kaplan-Meier survival analysis demonstrated a significantly shorter survival in patients showing TRPV1 mRNA down-regulation. Multivariate Cox regression analysis further indicated that TRPV1 mRNA expression retained its significance as an independent risk factor.

Conclusions: The progression of UC of human bladder is associated with a marked decrease of TRPV1 expression, with a progressive loss in high-grade muscle invasive UC. Downregulation of TRPV1 mRNA expression may represent an independent negative prognostic factor for the survival probability of bladder cancer patients. 


\section{Introduction}

Cancer of the bladder is the fourth most frequent cancer among men in Europe ${ }^{1}$ and the fifth most common cancer in United States. ${ }^{2}$ More than $90 \%$ of bladder carcinomas are urothelial carcinoma derived from the urothelium, $6 \%$ to $8 \%$ are squamous cell carcinomas and $2 \%$ are adenocarcinomas. ${ }^{3}$ About $70 \%$ of superficial (Ta and $\mathrm{T} 1$ ) tumors recur, and $10-20 \%$ are invasive. Of all diagnosed patients, up to $25 \%$ have muscle invasive tumors (pT2-pT4) at first presentation, but most patients (75-80\%) present non invasive (pTa) and superficial invasive (pT1) tumors. ${ }^{4,5}$

Clinico-pathological markers such as stage, grade, size, multifocality of transitional cell carcinoma (TCC), presence of carcinoma in situ, lymph node status and the risk of recurrence or progression of bladder tumours are currently the most useful parameters for making therapeutic decisions and evaluating the follow-up and prognosis of patients with bladder cancer. However, due to tumour heterogeneity and differences in the biological behavior of urothelial cancers (UCs), classical prognostic factors do not accurately predict the clinical outcome of many patients with bladder cancer, and great efforts in searching new and more powerful molecular markers have been made. ${ }^{6-8}$

Malignant cell transformation is often accompanied by changes in ion channel expression. ${ }^{9}$ Over the past decade, an increasing set of data have revealed that changes in transient receptor potential (TRP) channel expression are associated with cancer development and metastasis. ${ }^{10}$ TRPV1 is a non-selective cation channel structurally related to the members of TRP family of ion channels. It is activated by increased temperature with a threshold of about $43{ }^{\circ} \mathrm{C}$ at $\mathrm{pH}$ 7.4, and in addition to capsaicin (CPS), by lipoxygenase metabolites, endogenous endocannabinoids, and protons. ${ }^{11}$

TRPV1 is mainly expressed by primary sensory neurons involved in nociception and neurogenic inflammation; however, it can be also present in non neuronal cells. ${ }^{11,12}$ In the 
urinary bladder, TRPV1 is expressed within afferent nerve terminals, basal and apical urothelial cells and interstitial cells. ${ }^{13-16}$ As in other cell systems, pain perception was the first role attributed to TRPV1 in the urinary tract: ${ }^{17}$ in addition, a functional role of urothelial TRPV1 in normal bladder afferent mechanisms for perception of mechanical and irritant stimuli has been reported. ${ }^{18,19}$ Furthermore, an involvement of TRPV1 in cell differentiation has been recently suggested. ${ }^{20}$

Many evidences suggest that TRPV1 contributes to growth and progression of several malignancies $^{21,22}$ and increased TRPV1 expression has been found in prostate, colon, pancreas and bladder cancers. ${ }^{20,21,23,24}$ Moreover, we have previously shown that TRPV1 expression inversely correlates with glioma grade. ${ }^{\mathbf{2 5}}$

Little evidence concerning the expression and function of TRPV1 in human bladder cancer are available so far. In a cohort of 29 TCC patients, a loss of TRPV1 protein expression in the urothelium was observed, as TCC stage increases and cell differentiation decreases. ${ }^{20}$ In addition, we have recently reported the expression of TRPV1 in human UC cell lines and the involvement of this channel receptor in the apoptosis induced by the selective agonist CPS. CPS-induced apoptosis was associated with a rapid $\left[\mathrm{Ca}^{2+}\right]_{\mathrm{i}}$ influx, transcription of Fas/CD95 and members of Bcl-2 and caspase families, and with the activation of ATM/CHK2/p53 DNA damage response pathway. In UC cells, TRPV1 stimulation resulted in Fas/CD95 upregulation and clustering, and in the triggering of both intrinsic and extrinsic apoptotic pathways. $^{26}$

Aim of the present study was to evaluate TRPV1 mRNA and protein levels in patients with UCs of different grade and stage, and to correlate TRPV1 expression with clinicopathological parameters including patient survival. 


\section{Materials and methods}

\section{PATIENTS AND BLADDER SPECIMENS}

Specimens from normal bladder (NB) $(n=5)$ were obtained by multiple cold-cup biopsies during diagnostic cystoscopy (cystoscopic control during tension free vaginal tape [TVT] procedures for the treatment of female stress urinary incontinence). None of the patients had urinary tract infections, and the urodynamic assessment showed no functional disorders of the lower urinary tract. Macroscopic examination of the bladder mucosa did not show any pathology (cancer) at the time of diagnosis.

In this study we used bladder tissue samples from 62 adult patients undergoing transurethral resection of superficial UC ( $\mathrm{n}=25)$ or radical cystectomy for muscle-invasive bladder cancer $(n=37)$, enrolled between February 1999 and January 2007 at the Urology Operative Unit, ASUR 9, Macerata, Italy. All patients gave their consent, and a local ethics committee approved this study. All the specimens were embedded in paraffin, and 5-7 $\mu \mathrm{m}$ thick sections were collected on slides ( $n=8$, for each specimen) and processed for immunohistochemistry. Bladder tumours were histologically diagnosed according to the 1973 World Health Organization (WHO) classification system.

\section{RNA EXTRACTION AND REVERSE TRANSCRIPTION}

Total RNA from fixed paraffin-embedded tissue slices $(5-7 \mu \mathrm{m}$ thick) was isolated by Absolutly RNA ${ }^{\circledR}$ FFPE kit (Stratagene, Austin, TX, USA) as previously described. ${ }^{22}$ All RNA samples were eluted in the appropriate buffer and their concentration and purity were evaluated by $\mathrm{A}_{260 \mathrm{~nm}}$ measurement. Five hundred nanograms of RNA extracted were subjected to reverse transcription in a total volume of $50 \mu \mathrm{l}$ using the High-Capacity cDNA Archive Kit (PE Applied Biosystems, Foster City, CA) accordingly to the manufacturer's instructions. Two $\mu$ of the resulting cDNA products were used as template for PCR quantification. 


\section{QUANTITATIVE REAL-TIME PCR}

Quantitative Real Time PCR (qRT-PCR) was performed by using a IQ5 Multicolor Real time PCR Detection system (BioRad, Hercules, CA, USA). The reaction mixture contained the AB RQ Mix (AB Analitica, Padova, Italy). Human TRPV1 primers and probe were purchased as assay on demand by Applied Biosystems (Foster City, CA, USA). $\beta$-actin primers and probe sequence (forward 5'-CTGGAACGGTGAAGGTGACA-3'; reverse 5'CGGCCACATTGTGAACTTTG-3'; probe 5'-CAGTCGGTTGGAGCGAGCATCCC-3') were designed by Primer Express Software (PE Applied Biosystems) and purchased from Sigma Genosys (The Woodlands, TX, USA). The PCR parameters were $3 \mathrm{~min}$ at $95^{\circ} \mathrm{C}$ followed by 40 cycles of $95^{\circ} \mathrm{C}$ for $10 \mathrm{~s}$ and $60^{\circ} \mathrm{C}$ for $1 \mathrm{~min}$. All samples were assayed in triplicate in the same plate. The relative amount of target mRNA was calculated by the $2^{-\Delta \Delta \mathrm{Ct}}$ method, ${ }^{27}$ considering $\beta$-actin as housekeeping gene. The mean of TRPV1 expression in NB samples was used as reference value and considered as 1.

\section{HAEMATOXYLIN-EOSIN STAINING AND IMMUNOHISTOCHEMISTRY}

Haematoxylin-eosin staining confirmed that all the specimens classified as NB $(n=5)$ showed no dysplasia or carcinoma. Pathologic examination confirmed the presence of superficial UC in 25 patients and muscularis propria invasive UC in 37 patients. Table 1 summarizes the clinico-pathological parameters.

For immunohistochemistry, sections were treated with $\mathrm{H}_{2} \mathrm{O}_{2}$ for 20 min, washed, incubated for $1 \mathrm{~h}$ at room temperature with $3 \% \mathrm{BSA}$ and $0.3 \%$ Triton $\mathrm{X}-100$ in $0.1 \mathrm{M} \mathrm{PBS}$, and then overnight at $4{ }^{\circ} \mathrm{C}$ with a rabbit anti-TRPV1 polyclonal antibody (Ab) (1:25) from Santa Cruz Biotechnology (Santa Cruz, CA, USA). Thereafter, slides were incubated for $30 \mathrm{~min}$ at room temperature with a biotinylated secondary $\mathrm{Ab}(1: 200)$, rinsed, and exposed for $30 \mathrm{~min}$ to the streptavidin-biotin complex (ABC Elite Kit; Vinci Biochem, Vinci, Italy). Immunoreactivity was detected by the addition of diaminobenzidine (Sigma-Aldrich) for $10 \mathrm{~min}$. Finally, the 
sections were counterstained with hematoxylin for nuclei labelling. Four random fields of each tissue specimen were analyzed under 20x magnification by using the Olympus BX51 Microscope and the Image J software (National Institutes of Health, Bethesda, MD). The extent and the intensity of TRPV1 immunostaining were graded on a scale of 0-3 by two observers on two separate occasions using coded slides, and the average score was calculated. A 0 grade indicates immunonegativity and 3 strong positivity.

\section{STATISTICAL ANALYSIS}

Statistical analysis was performed by using Kruskal-Wallis test for comparison TRPV1 mRNA expression groups. $P$-value $\leq 0.05$ was considered significant. Patients follow-up was evaluated as the number of months from the date of the diagnostic surgical procedure to that of last visit or death. The survival time was defined as the period between the time of diagnosis and the time of death.

Statistical analysis of clinico-pathological and molecular parameters was performed using GraphPad Prism 5.0 software (GraphPad software, San Diego, CA, USA). Univariate survival analysis was performed according to Kaplan-Meier method, and differences in the survival curves were assessed with the Log-rank test. Multivariate survival analysis was performed using Cox's proportional regression analysis and the relative risk with $95 \%$ confidence interval $(\mathrm{CI})$ was calculated. A $P$-value $\leq 0.05$ was considered statistically significative. 
Results

PROGRESSIVE DECREASE OF TRPV1 mRNA EXPRESSION FROM SUPERFICIAL TO MUSCLE INVASIVE UC TISSUES

We evaluated TRPV1 mRNA expression in differently staged and graded UC specimens (Table 1) by qRT-PCR (Figure 1). The mean value of TRPV1 expression in NB tissues was Fig. 1 used as control. Starting from superficial pTa and pT1 towards the more invasive pT2, pT3 and pT4 stages, we observed a progressive down-regulation of TRPV1 mRNA expression, reaching very low levels in muscle-invasive pT3-pT4 (about 10 fold decrease with respect to normal tissue), $(\mathrm{p}<0.0001$; Figure $1 \mathrm{~A})$. Moreover, a gradual decrease of TRPV1 mRNA expression was observed as grade increased, independently from the stage, with significant loss of receptor expression in G3 tissues as compared to NB ( $p<0.001$, Figure 1B).

\section{LOSS OF TRPV1 PROTEIN IN HIGH STAGED MUSCLE INVASIVE UC TISSUES}

The results obtained by qRT-PCR in UC tissues prompted us to evaluate also the expression of TRPV1 protein by immunohistochemistry and semiquantitative analysis (Figure 2 and

Fig. 2; Tab.2 Table 2). As previously reported, ${ }^{18} \mathrm{NB}$ was immunoreactive, with superficial cells showing a higher staining than basal and club-shaped cells (Figure 2b); the labeling was intracytoplasmatic and mainly distributed in granular structures. Consistent with qRT-PCR data, a marked decrease up to an absence of TRPV1 labeling was found in UC specimens of high grades and stages as differentiation levels decreased, with faintly staining observed only in more superficial cells, but not in muscle-invading cells (Figure $2 \mathrm{f}$ and $2 \mathrm{~g}$ ). By contrast, in superficial UC specimens of cases staged as pTa, labeling intensity was similar or slightly lower than that observed in NB specimens. In the cases staged as pT1 and pT2 the labeling intensity was markedly reduced (Figure $2 \mathrm{c}$ and $2 \mathrm{~d}$ ). No reactivity was found with normal rabbit serum used as negative control (Figure 2a). Moreover, by semiquantitative analysis, no 
immunoreactivity was evidenced in pT3G3, pT4G3 stages and in the majority (75\%) of pT3G2 samples; weak immunoreactivity in 55\% of pT3 (G2 and G3) cases; moderate immunoreactivity in 50\% of pT1 (G2 and G3) and pTaG2 specimens, respectively; moderate $(67 \%)$ to strong immunoreactivity $(33 \%)$ in pTaG1 tumours; and finally strong staining in all NB specimens (Table 2). Finally, differently from data previously reported, ${ }^{20}$ we found that TRPV1 mRNA and protein expression was maintained in more differentiated superficial pTaG1 and pT1G2 UC tissues.

\section{TRPV1 EXPRESSION AND PATIENT SURVIVAL TIME}

TRPV1 mRNA expression was correlated with clinico-pathological parameters, including patient survival. In univariate analysis, cumulative survival curves were calculated according to the Kaplan-Meier method by evaluating conventional prognostic parameters such as: age, tumor grade, pT status, lymph node and distant diagnosed metastasis, and TRPV1 mRNA expression of all patients. Among them, other than lymph node invasion and the presence and distant diagnosed metastasis that are hugely powerful determinants of survival, tumor grade and TRPV1 mRNA expression reached Tab. 3 significance for survival (Table 3). Similar results were obtained in a subgroup of patients without diagnosed metastasis (M0) (Table 3; Figure 3). Thus, the reduced TRPV1 mRNA expression observed in UC patients strongly correlated with poor prognosis and short Fig. 3 survival.

We additionally performed a stratified multivariate analysis based on Cox regression model, to test the influence of the selected parameters (TRPV1 mRNA expression and tumor grade) on the survival of all patients or in a pT2/T3/T4 subgroup (Table 4). We found that the degree of TRPV1 expression retained its significance as an independent prognostic factor in all groups of patients $(P=0.004)$ and in the pT2/T3/T4 subgroup $(P=0.030)$. Moreover, the analysis of TRPV1 mRNA expression levels in a more homogeneous group of patients 
characterized by similar clinico-pathological tumor features (G2/G3, T2/T3, N0 M0), evidenced that TRPV1 mRNA represents an independent marker of the survival $(P=0.050)$ (Table 4). 


\section{Discussion}

Changes in TRP channel expression are associated with cancer development and metastasis. It has also been suggested that some TRP channels may serve as prognostic or diagnostic markers. ${ }^{10}$ Among the TRP superfamily, TRPV channels (TRPV1-6) are mainly involved in the regulation of growth and progression of genitourinary cancers. Thus, in prostate adenocarcinoma, TRPV1 and TRPV6 channels are overexpressed, with respect to healthy prostate tissues, and their expression levels strictly correlated with Gleason score, pathological stage, extraprostate extention and tumor grades. ${ }^{22,28,29}$ Moreover, a role for TRPV6 in survival, proliferation and resistance to apoptosis of LNCaP prostate cancer cells via a $\mathrm{Ca}^{2+} / \mathrm{NFAT}$ dependent pathway ${ }^{30}$ was reported together with a role of TRPV2 in the migration of prostate cancer cells in response to lysophospholipids. ${ }^{31}$

In bladder cancer, a progressive loss of TRPV1 protein expression in the urothelium, as TCC stage increased and cell differentiation decreased, was previously described. ${ }^{20}$ In addition, we recently demonstrated that stimulation of TRPV1 triggers the ATM/CHK2/p53 DNA damage response pathway and Fas/CD95-mediated intrinsic and extrinsic apoptotic pathways. ${ }^{26}$ Moreover, we reported the overexpression of TRPV2 full-length and a parallel reduction of its short-splice variant s-TRPV2 in tumors of increasing grade and stage. These findings suggest the existence of a negative feedback mediated by s-TRPV2 that controls the expression of TRPV2 full-lenght in UCs. ${ }^{32}$

In the present study, we found that TRPV1 is down-regulated in UC at both transcriptional and translational levels. Furthermore, more importantly, results from Kaplan-Meier analysis and Cox proportional hazards regression models suggest that reduced TRPV1 mRNA levels may be an independent prognostic marker for poor survival.

As previously reported, ${ }^{14,15,20}$ TRPV1 was expressed both at mRNA and protein levels in NB tissues $(n=5)$. The analysis of 62 UC specimens by qRT-PCR and immunohistochemistry evidenced a progressive decrease of TRPV1 mRNA and protein expression as UC stage 
increases, with a complete loss of TRPV1 protein in muscle invasive pT3 and pT4 stages. These findings are substantially in agreement with previous data; ${ }^{20}$ however, Lazzeri et al. showed a decreased TRPV1 protein expression in all superficial TCC examined, while we found decreased TRPV1 mRNA and protein expression in moderately differentiated pTaG2 and poorly differentiated pT1G3 UCs. This discrepancy could be related to the different techniques utilized and to the lower number of cases analyzed by Lazzeri et al. Remarkably, since the Ta and T1 stages of poorly differentiated UCs show increased recurrence and progression rate, and invasiveness, respectively, the significant reduction of TRPV1 mRNA we found in pTaG2 vs pTaG1 and pT1G3 vs pT1G2 may be particularly important in the evaluation of the stratification risk of recurrence and tumor progression of invasive versus not invasive superficial UCs. ${ }^{33}$

Altogether, our findings demonstrate an inverse correlation between TRPV1 (mRNA and protein) expression and the pathological stage and grade in UC tissues. This strongly suggests that TRPV1 expression is negatively associated with UC progression.

The question that now arises is what might be the patho-physiological relevance of TRPV1 expression to UC tumorigenesis. Our recent data indicate that triggering of TRPV1 on UC cells activates Fas-mediated intrinsic and extrinsic apoptotic pathways. ${ }^{26}$ Thus, it is conceivable that the reduced expression of TRPV1 represents an evasion mechanism by which the UC cells could evade anti-proliferative and pro-apoptotic signals. In support of this hypothesis, intravesical instillation of curcumin, a vanilloid-like molecule, by selective binding to TRPV1, inhibits TCC cell implantation and growth in a murine superficial bladder tumor model. ${ }^{34}$

To further address the potential prognostic value of this receptor, we correlated TRPV1 mRNA expression with the clinico-pathological parameters and patient's survival. By univariate analysis (Kaplan-Meier method), the cumulative survival curves for the canonic prognostic parameters such as tumor grade, lymph nodes and distant diagnosed metastasis 
reached significance. More important, the reduction of TRPV1 mRNA expression was associated with a shorter survival of all UC patients $(P=0.008)$ and the M0 subgroup $(P=$ 0.045). In a multivariate Cox proportional hazards regression model, TRPV1 expression reached significance as an independent prognostic factor for survival considering all patients and the subgroup characterized by invasive stage.

Taking in account that patients with metastasis generally have poor prognosis ${ }^{35}$, we selected a group of patients with similar tumor grade and stage, without distant diagnosed metastasis (M0) and lymph node positivity (N0); we observed that TRPV1 could successfully differentiate survival as a valuable and independent molecular marker.

Similarly, TRPV1 expression was recently evaluated in hepatocellular carcinoma (HCC) where it seems correlate to a better prognosis of patients suggesting that it could be potentially used as a prognostic indicator of HCC. ${ }^{36}$

In conclusion our results suggest that TRPV1 represents a potential prognostic marker for patients with urothelial carcinoma of the bladder. As an independent prognostic factor for poor disease outcome, TRPV1 may be useful to improve appropriate selection of postoperative follow-up protocols for individual patients. 


\section{References}

1. Ferlay J, Bray F, Pisani P et al. GLOBOCAN 2000: Cancer Incidence, Mortality and Prevalence Worldwide: Version 1,0. IARC Cancer Base No 5. IARC Press. Lyon: Cours Albert Thomas, 2001.

2. Sternberg CN, Calabro F. Chemotherapy and management of bladder tumours. BJU Int. $2000 ; 85 ; 599-610$.

3. Jemal A, Murray T, Ward E et al. Cancer statistics, 2005. CA Cancer J. Clin. 2005; 55; 1030.

4. Prout Jr GR. Bladder carcinoma and a TNM system of classification. J. Urol. 1977; 117; 583-590.

5. Scarpelli M, Montironi R, Tarquini LM et al. Karyometry detects subvisual differences in chromatin organization state between non-recurrent and recurrent papillary urothelial neoplasms of low malignant potential. J. Clin. Pathol. 2004; 57; 1201-1207.

6. Egawa S, Kuruma H. Search for biomarkers of aggressiveness in bladder cancer. Eur. Urol. 2006; 50; 20-22.

7. Yurakh AO, Ramos D, Calabuig-Farinas S et al. Molecular and Immunohistochemical analysis of the prognostic value of cell-cycle regulators in urothelial neoplasms of bladder. Eur. Urol. 2006; 50; 506-515. 
8. Thalmann GN. Prognostic markers for bladder cancer - Are we there yet? Eur. Urol. 2007; $51 ; 591-592$.

9. Kunzelmann K. Ion channel and cancer. J. Membrane Biol. 2005; 205; 159-173.

10. Gkika D, Prevarskaya N. Molecular mechanisms of TRP regulation in tumor growth and metastasis. Biochim. Biophys. 2009;1793;953-958.

11. Caterina MJ, Schumacher MA, Tominaga M, Rosen TA, Levine JD and Julius D. The capsaicin receptor: a heat-activated ion channel in the pain pathway. Nature $1997 ; \mathbf{3 8 9}$; 816824.

12. Amantini C, Mosca M, Lucciarini R et al. Distinct thymocyte subsets express the vanilloid receptor VR1 that mediates capsaicin-induced apoptotic cell death. Cell Death Differ. 2004; 11; 1342-1356.

13. Birder LA, Kanai AJ, de Groat WC et al. Vanilloid receptor expression suggests a sensory role for urinary bladder epithelial cells. Proc. Natl. Acad. Sci. U S A 2001; 98; 13396-13401.

14. Avelino A, Cruz F. TRPV1 (vanilloid receptor) in the urinary tract: expression, function and clinical applications. Naunyn Schmiedebergs Arch. Pharmacol. 2006; 373; 287-299.

15. Lazzeri M, Vannucchi MG, Zardo C et al. Immunohistochemical evidence of vanilloid receptor in normal human urinary bladder. Eur. Urol. 2004; 46; 792-798. 
16. Apostolidis A, Brady CM, Yiangou Y, Davis J, Fowler CJ, Anand P. Capsaicin receptor TRPV1 in urothelium of neurogenic human bladders and effect of intravescical resinferatoxin. Urology 2005; 65; 400-405.

17. Birder LA. More than just a barrier: urothelium as a drug target for urinary bladder pain. Am. J. Physiol. Renal Physiol. 2005; 285; 489-495.

18. Birder LA, Nakamura Y, Kiss S et al. Altered urinary bladder function in mice lacking the vanilloid receptor TRPV1. Nat. Neurosci. 2002; 5; 856-860.

19. Birder LA. TRPs in bladder diseases. Biochim. Biophys. Acta. 2007; 772; 879-884.

20. Lazzeri M, Vannucchi MG, Spinelli M et al. Transient receptor vanilloid type 1 (TRPV1) expression changes from normal urothelial to transitional cell carcinoma of human bladder. Eur. Urol. 2005; 48; 691-698.

21. Sanchez MG, Sanchez AM, Collado B et al. Expression of the transient receptor potential vanilloid 1 (TRPV1) in LNCaP and PC-3 prostate cancer cells and in human prostate tissue. Eur. J. Pharmacol. 2005; 515; 20-27.

22. Prevarskaya N, Zhang L, Barritt G. TRP channels in cancer. Biochim. Biophys. Acta. 2007; 1772; 937-946.

23. Domotor A, Peidl Z, Vineze A et al. Immunohistochemical distribution of vanilloid receptor, calcitonin-gene related peptide and substance $\mathrm{P}$ in gastrointestinal mucosa of patients with different gastrointestinal disorders. Inflammopharmacology. 2005; 13; 161-177. 
24. Hartel M, di Mola FF, Selvaggi F et al. Vanilloids in pancreatic cancer: potential for chemotherapy and pain management. Gut. 2006; 55; 519-528.

25. Amantini C, Mosca M, Nabissi M et al. Capsaicin-induced apoptosis of glioma cells is mediated by TRPV1 vanilloid receptor and requires p38 MAPK activation. J. Neurochem. $2007 ; 102 ; 977-990$

26. Amantini C, Ballarini P, Caprodossi S et al. Triggering of Transient Receptor Potential Vanilloid Type 1 (TRPV1) by Capsaicin induces Fas/CD95-mediated apoptosis of urothelial cancer cells in an ATM-dependent manner. Carc. 2009; 30:1320-1329.

27. Livak KJ, Schmittgen TD. Analysis of relative gene expression data using real-time quantitative PCR and the 2(-Delta Delta C(T) Method). Methods 2001; 25; 402-408.

28. Fixemer T, Wissenbach U, Flockerzi V, Bonkhoff H. Expression of the $\mathrm{Ca}^{2+}$-selective cation channel TRPV6 in human prostate cancer: a novel prognostic marker for tumor progression. Oncogene 2003; 22; 7858-7861.

29. Czifra G, Varga A, Nyeste K et al. Increased expression of cannabinoid receptor-1 and transient receptor potential vanilloid-1 in human prostate carcinoma. J. Cancer. Res. Clin. Oncol. 2009; 135; 507-514.

30. Lehen'kyi V, Flourakis M, Skryma R, Prevarskaya N. TRPV6 channel controls prostate cell proliferation via $\mathrm{Ca}^{2+} / \mathrm{NFAT}$-dependent pathways. Oncogene 2007; 26; 7380-7385. 
31. Monet M, Gkika D, Lehen'kyi V et al. Lysophospholipids stimulate prostate cancer cell migration via TRPV2 channel activation. Biochim. Biophys. Acta. 2009; 1793; 528-539.

32. Caprodossi S, Lucciarini R, Amantini C et al. Transient Receptor Potential Vanilloid Type 2 (TRPV2) Expression in Normal Urothelium and in Urothelial Carcinoma of Human Bladder: Correlation with the Pathologic Stage. Eur. Urol. 2008; 54; 612-620.

33. Millan-Rodriguez F, Chéchile-Toniolo G, Salvador-Bayarri J, Palou J, Algaba F, Vicente-Rodriguez J. Primary superficial bladder cancer risk groups according to progression, mortality and recurrence. J. Urol. 2000; 164; 680-684.

34. Sindhwani P, Hampton JA, Baig MM, Keck R, Selman SH. Curcumin prevents intravescical tumor implantation of the MBT-2 tumor cell line in C3H mice. J. Urol. 2001; 6; 1498-14501.

35. Furukawa J, Miyake H, Takenaka A, Fujisawa M. Clinical outcome of radical cystectomy for patients with pT4 bladder cancer. Int. J. Urol. 2008; 15; 58-61.

36. Miao X, Liu G, Xu X et al. High expression of vanilloid receptor-1 is associated with better prognosis of patients with hepatocellular carcinoma. Canc. Genet. Cytogenet. 2008; 186; 25-32. 
Table 1. Clinico-pathological characteristics of the 62 urothelial cancer (UC) patients analyzed for TRPV1 mRNA and protein expression.

\begin{tabular}{|c|c|}
\hline Patient characteristics & $n(\%)$ \\
\hline Age $[\mathrm{yr}]^{*}$ & $71.8(30-87)$ \\
\hline \multicolumn{2}{|l|}{ Sex } \\
\hline Male & $56(90.3)$ \\
\hline Female & $6(9.7)$ \\
\hline Follow-up time $[\mathrm{mo}]^{*}$ & $44.8(1-118)$ \\
\hline \multicolumn{2}{|l|}{ Survival } \\
\hline Alive & $42(67.7)$ \\
\hline Dead & $20(32.3)$ \\
\hline Tumor characteristics & $n(\%)$ \\
\hline \multicolumn{2}{|l|}{ His tologic classification } \\
\hline Transitional cell carcinoma & $62(100)$ \\
\hline \multicolumn{2}{|l|}{ Growth pattern ${ }^{\S}$} \\
\hline Papillary & $32(56.1)$ \\
\hline Solid & $20(35.1)$ \\
\hline Papillary/solid & $5(8.8)$ \\
\hline \multicolumn{2}{|l|}{ Pathologic stage } \\
\hline $\mathrm{pTa}$ & $8(12.9)$ \\
\hline pT1 & $16(25.8)$ \\
\hline pT2 & $18(29.0)$ \\
\hline pT3 & $12(19.4)$ \\
\hline pT4 & $8(12.9)$ \\
\hline \multicolumn{2}{|l|}{ Grading } \\
\hline G1 & $3(4.8)$ \\
\hline G2 & $30(48.4)$ \\
\hline $\mathrm{G} 3$ & $29(46.8)$ \\
\hline \multicolumn{2}{|l|}{ Pathologic lymph node stage } \\
\hline N0 & $56(90.3)$ \\
\hline $\mathrm{N} 1$ & $6(9.7)$ \\
\hline \multicolumn{2}{|l|}{ Metastases ${ }^{\S}$} \\
\hline M0 & $50(82)$ \\
\hline $\mathrm{M} 1^{\circ}$ & $11(18)$ \\
\hline \multicolumn{2}{|l|}{ TRPV1 mRNA fold expression } \\
\hline Low $(0.0<$ fold $\leq 0.5)$ & $25(40.3)$ \\
\hline Moderate $(0.5<$ fold $\leq 1.5)$ & $29(46.8)$ \\
\hline High (fold > 1.5) & $8(12.9)$ \\
\hline \multicolumn{2}{|c|}{ TRPV1 intracytoplasmatic staining } \\
\hline Score 0 & $20(32.3)$ \\
\hline 1 & $18(29.0)$ \\
\hline 2 & $18(29.0)$ \\
\hline 3 & $6(9.7)$ \\
\hline
\end{tabular}

* Data are presented as median and range (in parentheses).

$\S$ Numbers do not add up to 62 because of cases with missing data.

${ }^{\circ} \mathrm{M} 1$ was defined by the presence of metastasis during follow-up.

Published on behalf of the British Division of the International Academy of Pathology 
Table 2. Immunoreactivity of TRPV1 in normal bladder and urothelial carcinoma tissues at different pathologic stages.

\begin{tabular}{|c|c|c|c|c|c|c|}
\hline \multirow[t]{2}{*}{ Type } & & \multirow[t]{2}{*}{ N.cases } & \multicolumn{4}{|c|}{ * Score of TRPV1 expression } \\
\hline & & & 0 & 1 & 2 & 3 \\
\hline NB & & 5 & 0 & 0 & 0 & 5 \\
\hline \multirow[t]{2}{*}{ pTa } & G1 & 3 & 0 & 0 & 2 & 1 \\
\hline & G2 & 4 & 0 & 1 & 2 & 1 \\
\hline \multirow[t]{2}{*}{ pT1 } & $\mathrm{G} 2$ & 12 & 0 & 3 & 6 & 3 \\
\hline & G3 & 6 & 1 & 2 & 3 & 0 \\
\hline \multirow[t]{2}{*}{ pT2 } & $\mathrm{G} 2$ & 9 & 0 & 5 & 3 & 1 \\
\hline & G3 & 9 & 2 & 5 & 2 & 0 \\
\hline \multirow[t]{2}{*}{ pT3 } & $\mathrm{G} 2$ & 4 & 3 & 1 & 0 & 0 \\
\hline & G3 & 7 & 6 & 1 & 0 & 0 \\
\hline pT4 & G3 & 8 & 8 & 0 & 0 & 0 \\
\hline
\end{tabular}


Table 3. Univariate Kaplan-Meier survival analysis of clinico-pathological parameters and TRPV1 mRNA expression (log-rank test).

\begin{tabular}{|c|c|c|c|c|}
\hline & \multicolumn{2}{|c|}{ All patients $(n=62) \quad N^{\circ}$ events $(n=20)$} & \multicolumn{2}{|c|}{ M0 patients $(n=50) N^{\circ}$ events $(n=12)$} \\
\hline & Log-rank test & $p$ value & Log-rank test & $p$ value \\
\hline Age $(\leq 70 />70)$ & 0.29 & 0.588 & 0.80 & 0.372 \\
\hline Tumor Stage (pTa-1/pT2-4) & 2.21 & 0.137 & 0.57 & 0.449 \\
\hline Tumor grade (G1/G2/G3) & 10.17 & 0.006 & 7.80 & 0.020 \\
\hline TRPV1 (Low/ Moderate/ High) & 9.69 & 0.008 & 6.20 & 0.045 \\
\hline Lymph node stage (N0/N1) & 10.65 & 0.001 & - & - \\
\hline Metastasis (M0/M1) & 5.76 & 0.016 & not included & \\
\hline
\end{tabular}


Table 4. Multivariate Cox proportional hazard regression analysis of clinico-pathological parameters and TRPV1 mRNA expression in relation to survival rates.

\begin{tabular}{|c|c|c|c|c|c|}
\hline \multirow[b]{3}{*}{ TRPV1 (Low/ Moderate/High) } & \multicolumn{5}{|c|}{ Relative risk $(95 \% \mathrm{CI})$} \\
\hline & \multicolumn{2}{|c|}{ All patients $(n=62)$} & \multicolumn{2}{|c|}{$\mathrm{pTa} / \mathrm{T} 1(\mathrm{n}=24)$} & $\mathrm{pT} 2 / \mathrm{T} 3 / \mathrm{T} 4(\mathrm{n}=38)$ \\
\hline & $0.26(0.10-0.64)$ & $p=0.004$ & $0.61(0.07-5.03)$ & $p=0.651$ & $0.30(0.10-0.88) \quad p=0.030$ \\
\hline Tumor grade $(\mathrm{G} 1 / \mathrm{G} 2 / \mathrm{G} 3)$ & & & G2/G3 pT2/T3 N0I & $\operatorname{M0}(n=27)$ & \\
\hline TRPV1 (Low/Moderate/High) & & & $0.19(0.03-1.00)$ & $p=0.05$ & \\
\hline Tumor grade (G2/G3) & & & $5.65(0.68-47.0)$ & $p=0.111$ & \\
\hline Tumor stage (T2/T3) & & & $0.43(0.09-1.96)$ & $p=0.278$ & \\
\hline
\end{tabular}




\section{Figure legends}

Figure 1.

TRPV1 expression in UC tissues at different stages and grades. TRPV1 mRNA levels from UC tissues $(n=62)$ at different tumor stages (pTa-pT4) (A) and tumor grades (G1-G3) (B) were evaluated by qRT-PCR in triplicate. Results (mean \pm standard deviation) were normalized for $\beta$-actin expression and TRPV1 levels were expressed as relative fold with respect to NB tissues used as control. Data shown are representative of three separate experiments. $(* 0.01<p<0.05 ; * * 0.001<p<0.01$, Kruskal-Wallis test).

Figure 2.

Immunohistochemical analysis of TRPV1 protein in NB and UC tissues. Sections from paraffin-embedded NB, and UC tissues at different pathological stages (pTa-pT4) were immunostained with a rabbit anti-human TRPV1 polyclonal antibody. Images are representative of six slides for each UC stage. Magnification: X20. (a) Omission of the primary antibody; (b) NB specimen. (c-g) UC specimens staged as pTa-pT4. Size bars: 25 $\mu \mathrm{m}$. L: lumen.

Figure 3.

Kaplan-Meier survival analysis for M0 patients subgroup (no metastatic ones, $\mathrm{n}=50$ ) illustrating the association between:

A) Survival and TRPV1 mRNA expression based on three categories: high (fold $>1.5$ ), moderate $(0.5<$ fold $\leq 1.5)$ and low $(0.0<$ fold $\leq 0.5)$ expression. B) Survival and pathological grading divided into G1, G2 and G3 grades. Associated Log-Rank test $P$-values were indicated for each analysis. 


\section{Acknowledgements}

This study was supported by AIRC Regional Grant 2007; AIRC Regional Studentship 2008;

University of Camerino. 
Fig. 1
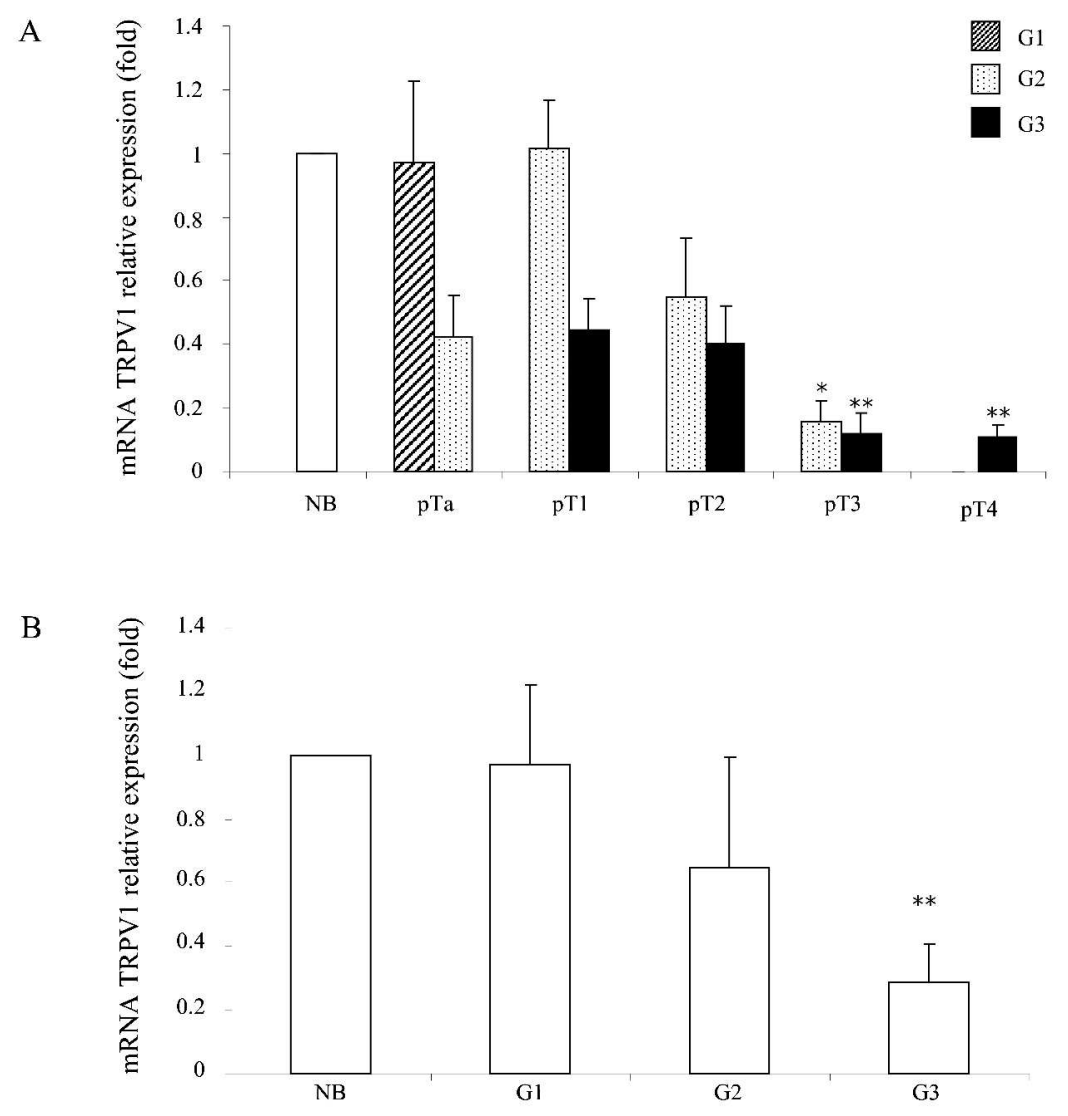

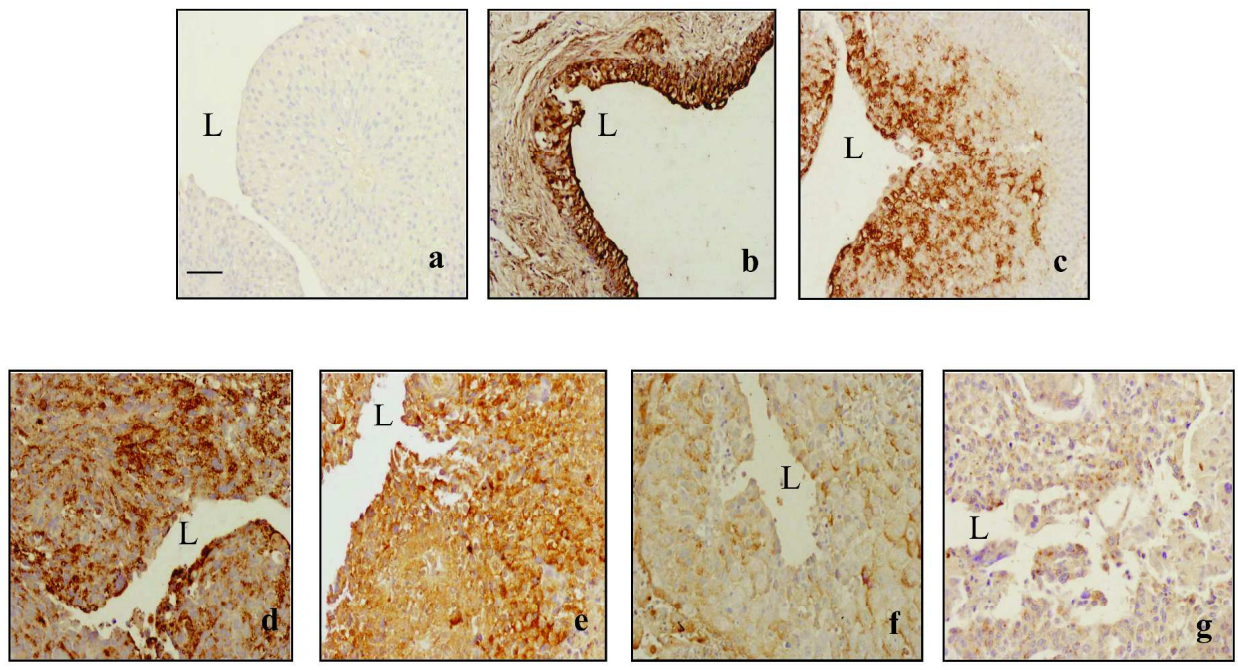

Fig. 2 
Fig. 3 A

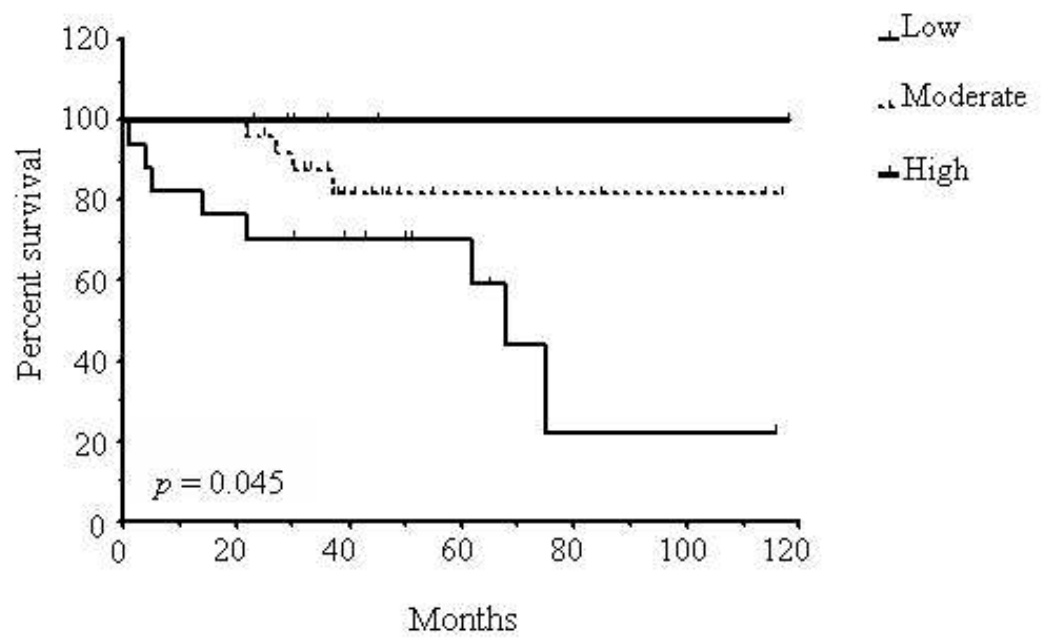

B

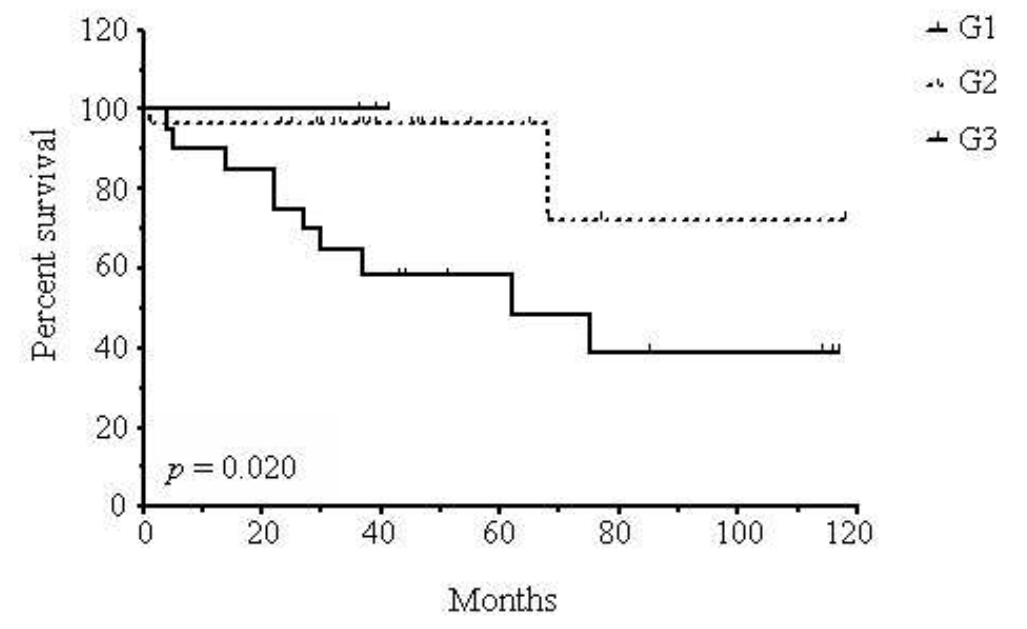

